\title{
IMPLEMENTASI MEDIA AUDIO VISUAL UNTUK MENINGKATKAN CRITICAL THINKING SISWA MENGGUNAKAN STRATEGI POINT COUNTERPOINT
}

\author{
Ahmad Muhibbin ${ }^{1}$, Ginda Tia Monika', Patmisari', Achmad \\ Muthali'in ${ }^{4}$ \\ 1,2,3,4 Universitas Muhammadiyah Surakarta, \\ am215@ums.ac.id, Gindatiamo98@gmail.com,patmisari@ums.ac.id, \\ am244@ums.ac.id
}

\begin{abstract}
ABSTRAK
Studi ini bertujuan untuk mendeskripsikan implementasi, efektivitas, kendala, dan solusi atas implementasi media audio visual menggunakan strategi point counterpoint pada siswa kelas XI TKJ A SMK Adi Sumarmo Colomadu tahun pelajaran 2020/2021. Penelitian ini menggunakan pendekatan mix methods dengan desain sequential exploratory. Sampel diambil menggunakan purposive sampling dengan jumlah 28 siswa. Teknik pengumpulan data kualitatif dengan wawancara, observasi, dokumentasi, sedangkan data kuantitatif dianalisis dengan uji hipotesis Pairde Sample T-Test. Uji keabsahan data menggunakan triangulasi sumber dan teknik, sedangkan uji validitas menggunakan Correlation Product Moment taraf signifikan 5\% diperoleh harga sebesar 0,444 dan reliabilitas menggunakan KR 20 dengan hasil 0,653. Analisis pada kualitatif menggunakan analisis model alir sedangkan kuantitatif menggunakan statistic deskriptif. Hasil penelitian ini yaitu implementasi media audio visual untuk meningkatkan critical thinking siswa menggunakan strategi point counterpoint dengan memberikan materi melalui WhatsApp Group dalam bentuk video. Efektivitas implementasi media audio visual menggunakan strategi point counterpoint dapat dilihat dari hasil rata-rata pretest 54,5 dan posttest sebesar 81,6 dengan jumlah soal sebanyak 20. Implementasi media audio visual menggunakan strategi point counterpoint mampu meningkatkan critical thinking siswa dengan hasil hipotesis thitung lebih besar dari ttabel $(15,144>1,700)$. Dalam penelitian ini mengalami kendala seperti keterbatasan waktu terkait pelaksanaan penelitian. Solusi alternatif untuk mengatasi kendala tersebut yaitu peneliti datang lebih awal dari jadwal penelitian dan harus pandai mengatur waktu dengan baik.
\end{abstract}

Kata Kunci: Petunjuk Penulisan; Media Audio Visual; Critical Thinking; Point Counterpoint 


\begin{abstract}
This study aims to describe the implementation, effectiveness, constraints, and solutions for the implementation of audio-visual media using the point-counterpoint strategy in class XI TKJ A SMK Adi Sumarmo Colomadu in the 2020/2021 school year. This study used a mixed-methods approach with a sequential exploratory design. Samples were taken using purposive sampling with a total of 28 students. Qualitative data collection techniques were interviews, observations, documentation, while quantitative data were analyzed using the Paired Sample T-Test hypothesis test. Test the validity of the data using triangulation of sources and techniques. The validity test using Correlation Product Moment with a significant level of 5\% obtained a price of 0.444 and reliability using KR 20 with a result of 0.653 . The qualitative analysis uses flow model analysis, while the quantitative analysis uses descriptive statistics. The results of this study are the implementation of audio-visual media to improve students' critical thinking using a point-counterpoint strategy by providing material through WhatsApp Group in the form of video. The effectiveness of the implementation of audio-visual media using the point-counterpoint strategy can be seen from the average results of the pretest 54.5 and posttest 81.6, with a total of 20 questions greater than $T$ table $(15,144>1,700)$. In this study, there were obstacles such as time constraints related to the implementation of the research. An alternative solution to overcome these obstacles is that researchers arrive earlier than the research schedule and must manage time well.
\end{abstract}

Keywords: Author Guidelines; Media Audio Visual; Critical Thinking; Point Counterpoint

\title{
PENDAHULUAN
}

Pendidikan adalah usaha sadar dan terencana untuk mewujudkan proses belajar mengajar agar siswa secara aktif mengembangkan potensi dirinya dalam hal spiritual keagamaan, pengendalian diri, masyarakat, bangsa dan negara sebagaimana tercantum dalam Undang-Undang Nomor 20 tahun 2003 tentang Sistem Pendidikan Nasional Pasal 1 ayat (1). ${ }^{1}$ Pendidikan bukan menjadi aspek penting dalam membebaskan manusia dari keterbelakangan, kebodohan, dan kemisminan. Akan tetapi hal ini bertolak belakang dengan kenyataan yang terjadi pada pendidikan di Indonesia. Pada kenyataannya, di tahun 2019 Indonesia mendapatkan rapor merah bahkan skornya turun di laporan Program For International Student Assessment (PISA). Hal ini dikarenakan masih terdapat disparitas pelayanan pendidikan antar sekolah negeri dan swasta

1 Departemen Pendidikan, "Undang-Undang Nomor 20 Tahun 2003 Tentang Sistem Pendidikan Nasional,” 33 Jakarta: Depdiknas § (2003), https://referensi.elsam.or.id/2014/11/ uu-nomor-20-tahun-2003-tentang-sistem-pendidikan-nasional/. 
daerah di Indonesia. Oleh karena itu diperlukan peningkatan kualitas dalam pembelajaran agar dapat berjalan efektif sesuai dengan sasaran dan tujuan pendidikan Indonesia. Sanggara mengemukakan bahwa pendidikan diberikan kepada siswa sejak lahir sampai dia mati. Pendidikan tersebut bertujuan untuk memberikan pengetahuan, penguasaan materi, bahkan tingkah laku dan perbuatan selama hidupnya diperoleh dengan pendidikan.

Pendidikan Pancasila dan Kewarganegaraan (PPKn) merupakan mata pelajaran yang diberikan di semua jenjang pendidikan, mulai tingkat dasar (SD), tingkat menengah pertama (SMP) sampai tingkat menengah atas (SMA), bahkan di tingkat perguruan tinggi yang menjadi mata kuliah wajib. Dalam Peraturan Menteri Pendidikan Nasional RI Nomor 24 Tahun 2006 pasal 37 dijelaskan bahwa: Pendidikan Pancasila dan Kewarganegaraan (PPKn) merupakan mata pelajaran yang wajib dalam kurikulum pendidikan di Indonesia karena mata pelajaran PPKn memfokuskan pada pembentukan warga negara yang memahami dan mampu melaksanakan hak-hak dan kewajiban untuk menjadi warga negara yang cerdas, terampil, dan berkarakter yang berlandaskan oleh pancasila dan UUD 1945. ${ }^{2}$

Tujuan PPKn adalah agar setiap orang menjadi warga negara yang baik, yakni warga negara yang memiliki kecerdasan, memiliki rasa bangga dan tanggung jawab serta mampu berpartisipasi dalam kehidupan masyarakat. ${ }^{3}$ Selain itu PPKn bertujuan untuk membentuk warga negara yang baik, warga negara yang kreatif, warga negara yang bertanggung jawab, warga negara yang cerdas, warga negara yang kritis, dan warga negara yang partisipatif. Warga negara yang bertanggung jawab atau disebut dengan civics responsibilities diartikan sebagai tanggung jawab terhadap dirinya, terhadap Tuhannya, terhadap manusia lain, terhadap lingkungan alam, serta terhadap masyarakat dan bangsa serta negaranya. ${ }^{4}$ Yang dimaksud dengan warga negara yang cerdas (civics intelligence) yaitu cerdas secara moral, spiritual, dan cerdas secara emosional. Proses pembelajaran yang menyenangkan menjadi salah satu faktor penentu keberhasilan pembelajaran. Ketika pembelajaran menyenangkan, maka siswa akan merasa senang untuk mencerna materi-materi yang dipelajari, sehingga mereka akan lebih mudah menerima dan mengerti dengan baik

2 Menteri Pendidikan Nasional RI, "Peraturan Menteri Pendidikan Nasional RI Nomor 24 Tahun 2006 Tentang Sistem Pendidikan Nasional" (2006).

3 Rosantiana NM, "Penerapan Media Audio Visual Untuk Meningkatkan Hasil Belajar Siswa Kelas VII Pada Pembelajaran PKn Di SMP Muhammadiyah 4 Semarang.," Penerapan Media Audio Visual Untuk Meningkatkan Hasil Belajar Siswa Kelas VII Pada Pembelajaran PKn Di SMP Muhammadiyah 4 Semarang. 1, no. 2 (2016): 1-58.

4 ridwan a Djou, "PEMANFAATAN INTERNET DALAM PEMBELAJARAN PENDIDIKAN PANCASILA DAN KEWARGANEGARAAN UNTUK MEMBANGUN KARAKTER SISWA," 2016. 
materi pelajaran. Siswa mengalami perkembangan dalam tingkat berpikirnya sehingga memerlukan stimulus dengan cara memperkaya pengalaman belajar yang bermakna melalui pemberian persoalan untuk memecahkan masalah atau fenomena yang berhubungan dengan aspek-aspek kehidupan manusia. Susilowati mengemukakan bahwa tantangan perubahan masa depan yang diiringi perkembangan ilmu pengetahuan adalah menuntut pembelajaran yang dapat meningkatkan kemampuan berpikir kritis siswa. Salah satu tujuan pembelajaran adalah melatih kemampuan keterampilan berpikir kritis siswa.

Menurut Iranto dan Suparno ${ }^{5}$ yang dimaksud dengan kemampuan berpikir kritis adalah kemampuan berpikir tingkat tinggi yang tujuannya untuk mengkaji situasi, fenomena, masalah atau pertanyaan untuk mendapatkan sebuah hipotesis atau kesimpulan untuk pengambilan keputusan secara rasional atas apa yang telah diyakini dan dikerjakan dengan melalui analisis, penafsiran, kesimpulan, evaluasi dan penjelasan. Peterampilan berpikir kritis penting untuk diajarkan kepada siswa, agar siswa dapat menolong dirinya dan orang lain dalam menghadapi masalah dalam kehidupan. ${ }^{6}$ Berpikir kritis menuntut 4 jenis ketrampilan di antaranya adalah keterampilan menganalisis, keterampilan melakukan sintesis, keterampilan memahami serta memecahkan masalah, dan keterampilan menyimpulkan. ${ }^{7}$ Dengan berpikir kritis, mereka mengambil peran penting dalam mendiskusikan permasalahan sehingga mereka dapat memecahkan solusi untuk itu. Proses pembelajaran yang membuat siswa berpikir kritis disebabkan oleh bahan ajar yang digunakan, sebagaimana kutipan berikut. By thinking critically, they take a significant role in discussing it so that they can solve a solution to it. A learning process that does not make students think critically is due to the instructional materials. ${ }^{8}$ Oleh karena itu diperlukan variasi strategi pembelajaran yang perlu dikuasai guru, agar proses belajar tidak monoton.

Salah satu strategi yang bisa digunakan untuk pembelajaran yang menarik adalah strategi point counterpoint. Yaitu kegiatan pembelajaran yang menggunakan teknik hebat untuk merangsang diskusi dan mendapatkan pemahaman dan minat pembelajaran yang lebih mendalam tentang berbagai isu

5 Dicky Iranto and S Suparno, "The Effects of Pbl Method Using the Hypermedia To the Students' Critical Thinking Skill on the Social Studies Subject," Jurnal Pendidikan Ekonomi Dan Bisnis (JPEB) 2, no. 2 (2014): 40, https://doi.org/10.21009/jpeb.002.2.3.

6 I Wayan Redhana, "Model Pembelajaran Berbasis Masalah Dan Pertanyaan Socratik Untuk Meningkatkan Keterampilan Berpikir Kritis Siswa," Jurnal Cakrawala Pendidikan, no. 3 (2013), https://doi.org/10.21831/cp.v0i3.1136.

7 F Faiz, Thinking Skill (Pengantar Menuju Berpikir) (Yogyakarta: Suka Press, 2012).

8 Achmad Muhibbin et al., "Data Analysis on Multiple-Intelligences as a Basis of Mapping and Increasing Independent Assignment Score in Civic Education Learning Based on Controversial Issues in Mass Media," International Journal of Scientific and Technology Research 8, no. 9 (2019): 621-26. 
yang diangkat dalam pembelajaran. ${ }^{9}$ Strategi pembelajaran point counterpoint adalah strategi yang memiliki pendekatan dalam pembelajaran yang sangat baik karena melibatkan siswa dalam mendiskusikan isu-isu kelompok secara mendalam yang dikemas dalam suasana yang tidak terlalu formal. ${ }^{10}$ Sebagai pendukung penggunaan strategi point counterpoint peneliti memilih media audio visual sebagai alat untuk mendukung proses pembelajaran dan berfungsi untuk memperjelas informasi yang disampaikan sehingga dapat mencapai tujuan pembelajaran yang sempurna.

Audio visual merupakan media instruksional modern yang sesuai dengan perkembangan zaman (kemajuan ilmu pengetahuan dan teknologi) dapat dilihat dan didengar. ${ }^{11}$ Media audio visual adalah media yang mempunyai unsur suara dan gambar. Jenis media ini mempunyai kemampuan yang lebih baik. Dapat disimpulkan bahwa yang dimaksud media audio visual adalah perantara atau penggunaan materi dan penyerapannya melalui pandangan maupun pendengaran sehingga membangun kondisi yang dapat membuat seseorang mampu memperoleh pengetahuan, keterampilan, serta sikap.

Studi-studi terdahulu menjelaskan pengaruh penerapan model PBL dengan media audio visual terhadap kemampuan berpikir kritis siswa. Hasil riset yang dilakukan Syaribuddin ${ }^{12}$ dengan menerapkan media audio visual terdapat perbandingan nilai rata-rata kelas menunjukkan bahwa kelas eksperimen memiliki nilai rata-rata yang lebih tinggi dibandingkan dengan kelas kontrol. Peneitian yang dilakukan oleh Suwadi ${ }^{13}$ dengan menerapkan strategi point counterpoint menunjukkan penerapan strategi pembelajaran point counterpoint dapat meningkatan daya kritis dan hasil belajar siswa. Terbukti ada kenaikan daya kritis siswa dari kondisi awal 13,33\% menjadi 28,57\% pada siklus I, dan $41,90 \%$ pada siklus II.

9 Melvin L Silberman, Active Learning : 101 Cara Belajar Siswa Aktif Terjemahan Raisul Muttaqien (Bandung: Nuansa, 2014).

10 Helbi Akbar Feni Nazela, Zulhaini, "Penerapan Metode Pembelajaran Kooperatif Tipe Point Counter Point Dalam Meningkatkan Motivasi Belajar Siswa Kelas Viii a Pada Mata Pelajaran Sejarah Kebudayaan Islam Di Mts Negeri Sentajo Filial Singingi Kecamatan Singingi Kabupaten Kuantan Singingi” (2019), http://ejournal.uniks.ac.id/Index.Php/Alhikmah/ Article/View/499.

11 Ahmad Rohani, Media Instruksional Edukatif (Jakarta: Rineka Cipta, 1997).

12 S. Syaribuddin, I. Khaldun, and M. Musri, "Penerapan Model Pembelajaran Problem Based Learning $(\mathrm{Pbl})$ Dengan Media Audio Visual Pada Materi Ikatan Kimia Terhadap Penguasaan Konsep Dan Berpikir Kritis Peserta Didik Sma Negeri 1 Panga," Jurnal Pendidikan Sains Indonesia (Indonesian Journal of Science Education) 4, no. 2 (2016): 96-105.

13 Suwadi Suwadi, "Penerapan Strategi Pembelajaran Point-Counterpoint Bervariasi Untuk Meningkatkan Daya Kritis Dan Hasil Belajar Pada Mata Pelajaran PKn Topik Usaha Pembelaan Negara Bagi Siswa Kelas IX E SMP Negeri 1 Mojosongo,” Teknodika 14, no. 1 (2016): 69, https://doi.org/10.20961/teknodika.v14i1.34703. 
Berdasarkan uraian tersebut, cukup penting melakukan penelitian yang berjudul "Implementasi Media Audio Visual Untuk Meningkatkan Critical Thinking siswa menggunakan Strategi Point Counterpoint". Minimnya riset terkait penggunaan media belajar untuk mendukung terwujudnya critical thinking memberikan peluang bagi peneliti untuk melakukannya. Tujuan penelitian ini adalah mendeskripsikan implementasi, efektivitas, kendala dan solusi media audio visual dan strategi point counterpoint untuk meningkatkan critical thinking siswa.

\section{Tinjauan Literatur}

\section{Media audio visual}

Dalam proses pembelajaran, guru perlu merencanakan pembelajaran yang baik dengan metode yang akan digunakan. Sebagai seorang isntruktir, guru tidak hanya menyampaikan isi buku maupun referensi lain. Selain metode yang baik, guru juga perlu merencanakan pengelolaan kelas, pendekatan yang akan digunakan, media pembelajaran atau alat peraga yang mendukung dan dapat membuat siswa tertarik atau senang dan suasana kelas terasa lebih hidup. Pembelajaran merupakan usaha sadar yang dilakukan guru untuk membantu siswa agar mampu belajar sesuai dengan minat dan kebutuhannya. ${ }^{14}$ Membuat media pembelajaran yang menarik akan mempermudah guru dalam menyampaikan materi pembelajaran. Pembelajaran yang dirancang perlu memperhatikan aspek kemajuan ilmu pengetahuan dan teknologi (IPTEK), karena pesatnya perkembangan ilmu pengetahuan dan teknologi semakin mendorong adanya pembaharuan. Pembaharuan tersebut perlu dimanfaatkan dalam proses belajar, karena adanya media pembelajaran sangat penting untuk menunjang keberhasilan siswa. ${ }^{15}$

Salah satu media yang dapat digunakan dalam proses pembelajaran yaitu media audio visual, dimana audio visual difokuskan pada video pembelajaran yang menempatkan pengalaman langsung tingkatan utama fokus belajar. Media pembelajaran audio visual merupakan suatu media pembelajaran yang dapat didengar suaranya, sedangkan yang dapat dilihat gambarnya secara langsung atau sering disebut dengan video. ${ }^{16}$ Pemanfaatan media audio visual sangat baik untuk meningkatkan berpikir kritis siswa dalam proses pembelajaran.

${ }^{14}$ R. Kustandi, C., Sucipto, B., \& Sikumbang, Media Pembelajaran: Manual Dan Digital (2nd Ed.). (Bogor: Ghalia Indonesia, 2013).

15 Kustandi, C., Sucipto, B., \& Sikumbang.

${ }^{16}$ Edy Suprianto, "Implementasi Media Audio Visual Untuk Meningkatkan Kemampuan Menulis Teks Eksplanasi," Trapsila: Jurnal Pendidikan Dasar 1, no. 02 (2020): 22, https://doi. org/10.30742/tpd.v1i02.810. 
Hal ini didukung oleh temuan Mursini ${ }^{17}$ yang menyatakan bahwa audio visual merupakan media yang mengandung unsur suara dan gambar yang dapat dilihat.

Menggunakan media audio visual diperlukan kemampian lebih karena mengandalkan dua indera sekaligus yaitu indera pendengaran dan penglihatan. Terdapat beberapa kelebihan media audio visual, pertama yaitu memberikan pesan yang dapat diterima secara lebih merta oleh peserta didik. ${ }^{18}$ Kedua, sangat bagus untuk menerangkan suatu proses. Ketiga, dapat mengatasi keterbatasan ruang dan waktu. Keempat, lebih realistik dapat diulang-ulang dan dihentikan sesuai dengan kebutuhan. Kelima, memberikan kesan mendalam yang dapat mempengaruhi sikap siswa. Diharapkan media tersebut dapat meningkatkan berpikir kritis siswa dalam proses pembelajaran.

\section{Critical thinking}

Critical thinking merupakan aktivitas atau kemampuan yang terdiri dari analisis fakta, menyusun gagasan dan mempertahankan gagasan tersebut dengan membuat perbandingan. Ketika berpikir, terdapat proses mempertimbangkan konsep, kemudian dianalisis berdasarkan fakta, berpikir secara luas dan kreatif untuk memecahkan masalah suatu permasalahan. Critical thinking bersifat reasonable dan bersikap reflektif yang difokuskan pada memutuskan apa yang harus dipercayai dan apa yang harus dilakukan. Dalam menggunakan critical thinking diperlukan ketelitian dan ketepatan dalam memutuskan permasalahan dan dapat mempercayai apa yang harus dilakukan ketika memecahkan sebuah permasalahan. Critical thinking juga diartikan sebagai kemampuan untuk memberi alasan secara tepat dan dapat dipercaya melalui evaluasi kualitas secara keseluruhan sehingga dapat dipercaya kebenarannya. Selain itu critical thinking juga merupakan kemampuan atau kecenderungan seseorang dalam membuat dan melakukan assessment terhadap kesimpulan berdasarkan dari berbagai bukti. ${ }^{19}$ Critical thinking berupa pemikiran yang masuk akal dan reflektif, berfokus untuk memutuskan apa yang harus dipercaya atau yang harus dilakukan. ${ }^{20}$

Berpikir kritis dalam proses pembelajaran perlu dilatih dan dikembangkan oleh guru. Kemampuan siswa untuk berpikir kritis tidaklah sama. Oleh karena

17 Mursini, Apresiasi Dan Pembelajaran Sastra Anak-Anak (Bandung: Cipta Pustaka Media Perintis, 2011).

18 Azhar Arsyad, Media Pembelajaran (Jakarta: Rajawali Press, 2011).

19 Yuyun Dwi Haryanti, "Model Problem Based Learning Membangun Kemampuan Berpikir Kritis Siswa Sekolah Dasar,” Jurnal Cakrawala Pendas (2017), https://doi.org/10.31949/ jcp.v3i2.596.

20 Ennis dalam Lesy Lusyawati, "ANALISIS KEMAMPUAN BERPIKIR KRITIS SISWA SMA MATERI ALAT INDERA MELALUI MODEL PEMBELAJARAN INQUIRY PICTORIAL RIDDLE,” 2017. 
itu berpikir kritis dapat dikatakan sebagai kemampuan berpikir secara reflektif dalam memutuskan persoalan. Untuk melatih berpikir kritis, siswa diberikan arahan untuk mencari maupun menemukan permasalahan, kemudian dianalisis. Dari analisis masalah tersebut disusun hipotesis dengen mengumpulkan data. Langkah selanjutnya adalah menguji hipotesis dan menentukan alternatif dari penyelesaian masalah tersebut. Maka dapat disimpulkan bahwa dalam critical thinking terdapat proses berpikir yang mendalam, mampu membeddakan dan menganalisis fakta dan opini yang bertujuan untuk pemecahan masalah dan pengambilan keputusan secara logis dan sistematis.

\section{Strategi point counterpoint}

Dalam perjalanan kehidupan bangsa Indonesia ke depan, berbagai tantangan dan persoalan selalu ada. Untuk menjawab berbagai tantangan dan persoalan yang ada, perlu dibentuk kebijakan dalam bidang pendidikan, salah satunya dengan pembentukan kurikulum 2013. Kurikulum selalu mengalami perubahan seiring dengan perkembangan zaman. Letak perubahan dsar pada kurikulum 2013 dibanding dengan kurikulum-kurikulum sebelumnya adalah pada tingkat satuan pendidikan. Untuk mencapai tujuan pembelajaran yang diinginkan, pendidik dalam memberikan materi kepada siswa dapat saling memperngaruhi, sehingga tercipta kegiatan pembelajaran yang baik. Pendidik yang awalnya masih menggunakan stratefi pembelajaran konvensional atau sederhana, perlu mengubah strategi pembelajaran yang efektif dan inovatif. Hal ini sangat menentukan keberhasilan belajar siswa karena di dalam strategi pembelajaran memuat prinsip-prinsip dasar kegiatan dan memberikan arahan perkembangan siswa. Salah satu bentuk strategi pembelajaran yang mampu menciptakan suasana belajar yang menarik dan menyenangkan yaitu dengan strategi point counterpoint. Strategi ini bertujuan untuk melatih siswa agar mampu menemukan argumentasi yang kuat dalam pemecahan masalah yang actual sesuai dengan perannya dalam masyarakat.

Strategi pembelajaran point counterpoint dilakukan dengan memberikan kesempatan kepada peserta didik untuk menyampaikan argumen dan persoalan yang muncul atau yang sengaja dimunculkan dalam proses pembelajaran. Dalam strategi ini berdasarkan aturan-aturan dan untuk menumbuhkan rasa percaya diri kepada siswa. Dengan strategi point counterpoint, peserta didik emmiliki kesempatan yang luas untuk akktif dlam mengemukakan pendapat dan berpikir kirits tentang persoalan yang muncul atau yang sengaja dimunculkan sesuai dengan materi pembelajaran. ${ }^{21}$ Selain itu, dengan strategi ini memberikan

21 Widarto, Pardjono, and Noto Widodo, "Pengembangan Model Pembelajaran," Cakrawala Pendidikan XXXI, no. 3 (2012): 409-23. 
kesempatan kepada siswa untuk mendiskusikan isu-isu kompleks secara mendalam, sehingga dapat meningkatkan kemampuan berpikir kritis siswa.

\section{METODE PENELITIAN}

Penelitian ini menggunakan gabungan antara metode kuantitatif dan kualitatif (Mix Methods). Mix methods merupakan metode penelitian dengan mengkombinasikan antara dua metode penelitian sekaligus, kualitatif dan kuantitatif dalam suatu kegiatan penelitian. ${ }^{22}$ Sehingga akan memperoleh data yang lebih komprehensif, valid, reliable, dan objektif. Desain dalam penelitian kualitatif menggunakan model alir sedangkan kuantitatif menggunakan desain One Group Pretest Posttest.

\section{Pengumpulan dan analisis data Kualitatif}

Teknik pengumpulan data merupakan hal yang paling utama dalam penelitian tujuan untuk mendapatkan data. ${ }^{23}$ Penggunaan teknik pengumpulan data yang tepat dalam penelitian memungkinkan diperolehnya data dan hasil yang objektif. Teknik pengumpulan data dilakukan dengan cara wawancara, observasi, dan dokumentasi. Observasi dilakukan pada siswa kelas XI TKJ A yang berkaitan dengan indikator sebagaimana ditampilkan pada tabel 1 . Wawancara dilakukan dengan guru mata pelajaran, dan siswa secara terstruktur menggunakan pedoman wawancara. Dokumentasi diambil dari proses pembelajaran daring berlangsung. Penelitian ini menggunakan dua macam triangulasi yaitu triangulasi teknik dan triangulasi sumber data. Triangulasi teknik berupa pengumpulan data dari hasil observasi dan wawancara, sedangkan triangulasi sumber data dalam penelitian ini berasal dari informan yaitu seluruh siswa kelas XI TKJ A SMK Adi Sumarmo Colomadu. Untuk menjaga etika dan kerahasiaan data yang diambil maka informasi yang telah terkumpul diberi simbol atau singkatan nama dari narasumber. Analisis data pada penelitian ini menggunakan teknik atau model analisis mengalir karena setiap tahap saling berhubungan dan kesimpulan sebagai hasil proses yang terjadi hanya satu kali. Pada tahap analisis model alir meliputi reduksi data, penyajian data, penarikan kesimpulan dan verifikasi.

\section{Pengumpulan dan analisis data Kuantitatif}

Penelitian ini menggunakan desain penelitian pre-eksperimental dengan One Group Pretest Posttest Design. Teknik analisis data menggunakan T-test dengan menganalisis skor rata-rata sebelum (pretest) dan sesudah (posttest) 2018).

22 Sugiyono, Metode Penelitian Kuantitatif, Kualitatif Dan $R \& D$ (Bandung: Alfabeta, 23 Sugiyono. 
dengan 4 opsional jawaban terdiri dari satu jawaban benar dan tiga jawaban salah.

Uji instrumen Perhitungan validitas instrumen menggunakan rumus korelasi product moment dengan angka kasar. Sedangkan Reliabilitas instrumen pada penelitian ini menggunakan rumus KR.20 dengan instrumen skor 1 berarti benar dan 0 salah. Uji persyaratan berupa normalitas menggunakan Lilliefors dan homogenitas menggunakan teknik Bartlett. Uji hipotesis menggunakan rumus Paired Sample T-test. Teknik analisis menggunakan statistik deskriptif.

\section{HASIL DAN PEMBAHASAN}

\section{Implementasi Media Audio Visual untuk Meningkatkan Critical Thinking Siswa Menggunakan strategi Point Counterpoint.}

Pembelajaran dengan menerapkan pengembangan media audio visual dengan strategi point counterpoint termasuk dalam pembelajaran inovatif dimana siswa lebih banyak berperan aktif dalam pembelajaran dibandingkan dengan guru. Model pembelajaran ini sejalan dengan teori konstruktivisme yang menekankan agar individu secara aktif menyusun dan membangun pemahaman dan pengetahuan. Pengembangan model pembelajaran ini di mendorong siswa untuk lebih memahami dan mendalami materi yang disampaikan sehingga dapat diterapkan dalam kehidupan dimasyarakat. teori ini memandang bahwa belajar adalah lebih dari sekedar mengingat. Inti sari teori konstruktivisme bahwa peserta didik harus menemukan dan mentransformasikan informasi kompleks ke dalam dirinya sendiri.

Dalam penelitian ini proses pembelajaran secara daring (dalam jaringan), sehingga siswa dan guru dituntut untuk menggunakan teknologi. Berdasarkan wawancara dengan guru beliau mengungkapkan:

"Proses pembelajaran yang dilakukan pada masa pandemi memanfaatkan WhatsApp dan Youtube. adapun menggunakan Google Classroom tetapi tidak efektif, banyak siswa yang tidak mengikuti atau mengirimkan tugas sesuai dengan waktu yang ditentukan. Jadi segala kegiatan pembelajaran diberikan melalui aplikasi tersebut"

Pembelajaran menggunakan media audio visual dalam pelaksanaannya dengan strategi point counterpoint dimana siswa akan diajak berdiskusi dan berpendapat sesuai dengan peran yang dimainkannya. Dalam pembelajaran ini siswa akan diajak mengutarakan pendapat, dan mempertahankan pendapatnya secara kritis.

Perlakuan diberikan kepada siswa kelas XI TKJ A SMK Adi Sumarmo Colomadu tahun pelajaran 2020/2021. Perlakuan dilakukan secara daring melalui grup WhatsApp. Tahap pertama siswa dibagi dalam 5 kelompok yang terdiri dari 5 sampai 6 orang dan setiap kelompok mendapat peran masing- 
masing. kemudian memberikan materi kepada siswa mengenai Mewaspadai Ancaman Terhadap kedudukan Negara Kesatuan republik Indonesia berupa video. Selanjutnya peserta didik diminta untuk memberikan argumen terkait materi sesuai dengan peran yang diberikan. kelompok lain memberikan sanggahan atau masukan kepada kelompok yang bertugas. diakhir pembelajaran guru memberikan kesimpulan sesuai dengan materi diskusi.

\section{Efektifitas Implementasi Media Audio Visual Untuk Meningkatkan Critical Thinking Siswa Menggunakan Strategi Point Counterpoint}

Pembelajaran PPKn menggunakan media audio visual dan strategi point counterpoint untuk meningkatkan critical thinking siswa. Hasil riset menunjukkan bahwa peneliti ini berhasil meningkatkan critical thinking melalui penggunaan media audio visual dan strategi point counterpoint. Terbukti terdapat perbedaan dari hasil data yang diperoleh dari pretest dan posttest. berdasarkan penelitian yang dilakukan sudah terealisasikan dengan baik. Hal ini dapat dibuktikan pada saat proses pembelajaran berlangsung. Secara sederhana implementasi bisa diartikan sebagai pelaksana atau penerapan. Implementasi adalah suatu pelaksanaan atau penerapan yang dilakukan dengan sungguh-sungguh untuk mencapai suatu tujuan tertentu. Critical Thinking adalah suatu kemampuan yang dimiliki seseorang untuk menggunakan pemikiran dasar menganalisis argumen dan membawa wawasan peserta didik pada setiap interpretasi, untuk meningkatkan pola penalaran yang kohesif dan koheren, merumuskan masalah, dengan melakukan deduksi dan induksi, serta menentukan keputusan yang tepat. Hal ini memiliki kesamaan dengan Rachmantika \& Wardono ${ }^{24}$ yang mendefinisikan critical thinking sebagai suatu sikap mau berpikir secara mendalam tentang masalah-masalah dan hal-hal yang berada dalam jangkauan pengalaman seseorang, pengetahuan tentang metode-metode pemeriksaan dan penalaran yang logis, dan semacam suatu keterampilan untuk menerapkan metode-metode tersebut. Jadi Critical Thinking merupakan sikap atau kemampuan yang dimiliki peserta didik untuk meningkatkan penalaran atau argumen. Strategi point counterpoint adalah strategi pembelajaran untuk melatih keterampilan siswa berbicara dan keterampilan mengungkapkan argumen dan sanggahan, maka debat merupakan strategi yang cukup efektif. Implementasi disini menjelaskan tentang bagaimana pelaksanaan atau penerapan media audio visual untuk meningkatkan critical thinking dengan menggunakan strategi point counterpoint di smk adi sumarmo colomadu.

${ }^{24}$ Arfika Riestyan Rachmantika and Wardono, "Peran Kemampuan Berpikir Kritis Siswa Pada Pembelajaran Matematika Dengan Pemecahan Masalah," in Prosiding Seminar Nasional Matematika, vol. 2, 2019, 441. 
Penelitian ini diperkuat dengan beberapa hasil riset yang menjelaskan pengaruh media audio visual terhadap critical thinking menggunakan strategi point counterpoit. Penelitian yang dilakukan oleh Hasnur ${ }^{25}$ dengan menerapkan strategi point counterpoint dapat meningkatkkan berpikir kritis siswa. Terbukti kemampuan berpikir kritis siswa sebelum tindakan hanya mencapai 38,5\% atau masih tergolong kurang baik. Setelah dilakukan tindakan kelas pada siklus I kemampuan berpikir kritis siswa meningkat menjadi 54,5\% atau tergolong cukup baik. Kemudian pada siklus II terjadi peningkatan menjadi $81,1 \%$ atau tergolong sangat baik karena berdada pada rentan $81 \%-100 \%$. Hasil riset yang dilakukan oleh Hapsari ${ }^{26}$ dengan menerapkan pengembangan model role playing dan strategi point counterpoint kemampuan berpikir kritis siswa meningkat. Kemampuan berpikir kritis yang mucul ditunjukan dari aktivitas siswa, yaitu siswa mampu menalar permasalahan, dapat berpikir secara reflektif atau berpikir aktif dalam mengenali masalah, dapat bertanggung jawab atas pendapatnya, dan siswa dapat secara mahir serta terampil dalam mengutarakan pendapatnya. Hasil riset yang dilakukan Susilowati ${ }^{27}$ penerapan model problem based learning berbantu media audio visual dapat meningkatkan kemampuan berpikir kritis pada siswa kelas 4 SD Negeri Ledok 07 Salatiga. Peningkatan ini dapat dilihat dari perolehan skor rata-rata adalah 48,1 dengan nilai kemampuan berpikir 64,2 tergolong pada keriteria "Tidak kritis" dengan persentase jumlah siswa minimal cukup kritis 44,8\%. Pada data siklus II nilai kemampuan berpikir kritis meningkat skor rata-rata menjadi 61,03 dengan nilai kemampuan berpikir kritis 87,2 Yang tergolong pada kritieria "kritis" dengan persentase jumlah siswa yang minimal cukup kritis mencapai 96,5\%. Dapat disimpulkan bahwa penerapan media audio visual dengan menggunakan strategi point counterpoint dapat meningkatkan kemampuan berpikir kritis siswa.

Implementasi media audio visual untuk meningkatkan critical thinking dengan menggunakan strategi point counterpoint di SMK Adi Sumarmo Colomadu proses pembelajaran berjalan baik sesuai dengan yang diharapkan. Dalam pelaksanaannya siswa mengikuti proses pembelajaran dengan tertib dan siap menerima mata pelajaran baru, siswa dibagi beberapa kelompok

25 MUHAMMAD ARIF HASNUR, "Penerapan Strategi Point Counter Point Untuk Meningkatkan Kemampuan Berpikir Kritis Siswa Pada Tema Makanan Sehat Muatan Ips Kelas V Madrasah Ibtidaiyah Al-Ikhwan Pekanbaru" (2020).

26 Laela Dwi Hapsari, "PENGEMBANGAN MODEL PEMBELAJARAN ROLE PLAYING DENGAN STRATEGI POINT-COUNTER-POINT UNTUK MENINGKATKAN KEMAMPUAN BERPIKIR KRITIS SISWA (STUDI KASUS PADA KELAS X IIS 2 SMA NEGERI 1 UNGARAN MATA PELAJARAN SOSIOLOGI TAHUN 2015/2016)," Journal of Chemical Information and Modeling 53, no. 9 (2013): 1689-99.

27 Rini Susilowati, "Penerapan Model Problem Based Learning Berbantu Media Audio Visual Untuk Meningkatkan Berpikir Kritis Kelas 4 Sd," Jurnal Imiah Pendidikan Dan Pembelajaran 2, no. 1 (2018), https://doi.org/10.23887/jipp.v2i1.13870. 
yang terdiri dari 5 sampai 6 siswa kemudian setiap kelompok mendapat peran masing-masing, guru memberikan materi dalam bentuk video yang dikirim melalui WhatsApp group, peserta didik diminta untuk memberikan argumen terkait materi sesuai dengan peran yang diberikan, kelompok lain memberikan sanggahan atau masukan kepada kelompok yang bertugas, diakhir pembelajaran guru memberikan kesimpulan sesuai dengan materi diskusi.

Hal tersebut memiliki kesamaan dengan pendapat Fitrianita ${ }^{28}$, guru memilih isu-isu yang mempunyai beberapa perspektif, guru membagikan kelompok, masing kelompok menyiapkan argumennya, kumpulkan kembali semua siswa dengan catatan, mulai debat dengan mempersilahkan kelompok mana saja yang akan memulai, mintalah tanggapan, bantahan atau koreksi dari kelompok lain perihal isu yang sama, lanjutkan proses ini sampai waktu yang memungkin, rangkum debat dari argumen-argumen yang muncul. Penjelasan diatas menunjukkan bahwa penelitian ini dapat dikaitkan dengan pendapatpendapat ilmiah sebagai kajian teori.

\section{Kendala dan solusi implementasi media audio visual untuk meningkatkan critical thinking menggunakan strategi point counterpoint}

Banyak kendala yang dihadapi guru sebagai pendidik dan pengajar selama proses pembelajaran daring masa pandemic Covid-19. Akibat dari pandemic tersebut proses pembelajaran yang semula tatap muka berubah dengan banyak dilakukan secara daring. Setiap guru memiliki solusi yang berbeda-beda untuk menghadapi kendala-kendala tersebut. Dalam pembelajaran daring banyak memanfaatkan teknologi seperti Handphone dan juga banyak memerlukan kuota internet. Adapun kendala dalam pembelajaran daring, banyak siswa yang minim kuota internet sehingga untuk mengikuti proses pembelajaran banyak yang terlambat. Solusi yang yang diberikan guru yaitu bergabung dengan temannya yang punya Wifi dirumah maksimum 3 siswa dan mematuhi protocol kesehatan.

Kendala lain dalam melakukan implementasi media audio visual untuk meningkatkan critical thinking siswa menggunakan strategi point counterpoint pada pembelajaran PPKn yaitu kurangnya motivasi dan semangat belajar siswa. Banyak peserta didik yang menyepelekan proses pembelajaran dan tidak mengirimkan tugas dengan alasan tidak memiliki kuota internet. Pernyataan ini diperkuat dengan hasil wawancara dengan guru PPKn yang memberikan pernyataan.

28 YULIA FITRIANITA, "Peningkatan Minat Belajar Siswa Pada Pembelajaran Ips Di Kelas Iva Dengan Strategi Point Counter Point Sd Negeri 28 Batang Anai Palapa Saiyo” (Universitas Bung Hatta, 2014). 
"kendala yang dihadapi dalam proses pembelajaran daring saat ini kondisi ekonomi setiap siswa itu berbeda-beda, 50\% keadaan ekonomi mereka menengah kebawah. Hal ini yang membuat siswa sulit untuk mengikuti proses pembelajaran secara daring karena dengan alasan bahwa tidak memiliki kuota. Tetapi pada kenyataannya, tidak adanya motivasi siswa untuk belajar dan mengirimkan tugas. Kuota yang seharusnya digunakan untuk kegiatan belajar hanya untuk bermain game"

Untuk mengatasi kendala tersebut dari pihak sekolah sudah memberi bantuan kuota kepada setiap siswa. Dari pihak guru yang bersangkutan juga memberikan kelonggaran waktu untuk mengirimkan tugas. Meskipun nilai yang diberikan berbeda-beda sesuai dengan ketepatan pengiriman tugas. Kendala yang dihadapi guru maupun siswa sama-sama dapat menghambat proses pembelajaran dan banyak siswa yang tertinggal materi.

Kendala lain dalam melakukan implementasi media audio visual untuk meningkatkan critical thinking siswa menggunakan strategi point counterpoint pada pembelajaran PPKn ialah karena adanya keterbatasan penggunaan strategi, materi, sasaran, lingkungan sasaran, dan waktu yang kurang tepat. Pada penelitian ini penyampaian materi melalui video yang di share di WhatsApp group, sehingga saat proses pembelajaran berlangsung siswa diarahkan untuk melihat materi tersebut. Pada saat di forum pembelajaran menggunakan WhatsApp grup sebagai sarana diskusi, absensi, dan pengumpulan tugas. waktu yang sangat terbatas membuat peneliti harus pintar-pintar memanfaatkan waktu dengan baik, karena waktu proses pembelajaran hanya $2 \times 20$ setara dengan 40 menit ( 2 jam pelajaran). Penggunaan strategi point counterpoint sebenarnya sangat menyita waktu, maka dari itu peneliti harus dapat memanfaatkan waktu dengan optimal. Solusi alternatif untuk mengatasi kendala yaitu harus pandai mengatur waktu dengan baik dan dapat memanfaatkan waktu dengan optimal.

\section{Tabel 1. Indikator critical thinking}

\begin{tabular}{ll}
\hline $\begin{array}{c}\text { Indikator Critical } \\
\text { Thinking }\end{array}$ & \multicolumn{1}{c}{ Keterangan Indikator Critical Thinking } \\
\hline Interprestasi & $\begin{array}{l}\text { Mampu memahami dan mengekspresikan arti atau makna yang } \\
\text { diperoleh dari berbagai pengalaman, situasi, data, peristiwa, peniaian, } \\
\text { aturan-aturan, prosedur atau kriteria yang bervariasi. }\end{array}$ \\
\hline Analisis & $\begin{array}{l}\text { Mampu identifikasi hubungan secara inferensial antara pernyataan, } \\
\text { pertanyaan, konsep, deskripsi, data atau bentuk representasi } \\
\text { lainnya yangd imaksudkan secara actual. Hal ini ditujukan untuk } \\
\text { mengekspresikan keyakinan, penilaian, pengalaman, alasan, informasi } \\
\text { ataupun pendapat. }\end{array}$ \\
\hline
\end{tabular}


Evaluasi

Mampu memberikan penialaian kredibilitas suatu pernyataan atau representasi lain berupa deskripsi persepsi, pengalaman, alasan, informasi maupun pendapat dan untuk menilai kekuatan loggis dari hubungan inferensial yang actual yang dimaksud dalam pernyataan, deskripsi, berupa pertanyaan atau bentuk representasi yang lain.

Inferensi Mampu mengidentifikasi dan menetapkan unsur-unsur yang akan digunakan untuk menarik kesimpulan sesuai akal; merumuskan dugaan dan hipotesis, mempertimbangkan informasi yang rekevan dan mengurangi konsekuensi dari data, pernyataan, prinsip, bukti, penilaian, keyakinan, pendapat atau bentuk representasi lainnya.

Sumber: Lestari 29

Tabel 2. Uji validitas dan reliabilitas

\begin{tabular}{cccc}
\hline Uji & Teknik & Hasil & Keterangan \\
\hline Validitas & Product Moment & 0,444 & Valid \\
\hline Reliabilitas & KR. 20 & 0,653 & Sangat Tinggi \\
\hline
\end{tabular}

Sumber: Data primer diolah dengan Excel (2021)

Tabel 3. Hasil perhitungan normalitas liliefors

\begin{tabular}{llll}
\hline & \multicolumn{1}{c}{$\mathrm{L}_{\text {himeng }}$} & $\mathrm{L}_{\text {tahel }}$ \\
\hline Pretest & 0,122 & 0.167 & \\
\hline posttest & 0.151 & 0.167 \\
\hline
\end{tabular}

Sumber: Data rimer diolah dengan Excel (2021)

Tabel 4. Hasil perhitungan homogenitas bartlett

\begin{tabular}{ccc}
\hline Taraf Signifikan & $\mathrm{H}_{\text {hitumg }}$ & $\mathrm{H}_{\text {tahel }}$ \\
\hline $0,05 \mathrm{dk}(95 \%)$ & 17,5 & 22,6 \\
\hline Sumber
\end{tabular}

Sumber: Data primer diolah dengan Excel (2021)

Tabel 5. Data pretest dan posttest

\begin{tabular}{lcc}
\hline & Pretest & Posttest \\
\hline Jumlah Sampel & 28 & 28 \\
\hline Mean & 54.5 & 81.6 \\
\hline Median & 55 & 82.5 \\
\hline Mode & 60 & 85 \\
\hline Standar Deviasi & 9.66 & 6.24 \\
\hline Skor Tertinggi & 70 & 90 \\
\hline Skor Terendah & 40 & 70 \\
\hline
\end{tabular}

Sumber: Data primer diolah dengan Excel (2021)

29 Rahayu Lestari, "Bimbingan Kelompok Dengan Teknik Mind Mapping Untuk Meningkatkan Kemampuan Critical Thinking Dan Career Decision” (2019). 
248 Ahmad Muhibbin dkk, Implementasi Media Audio Visual

Tabel 6. Hasil uji paired sample t-test

\begin{tabular}{ccc}
\hline $\mathrm{T}_{\text {himugg }}$ & $\mathrm{T}_{\text {thal }}$ & Level of Significant \\
\hline 15,144 & 1,700 & 0.05 \\
\hline Sumber: Data primer diolah dengan Excel (2021)
\end{tabular}

Gambar

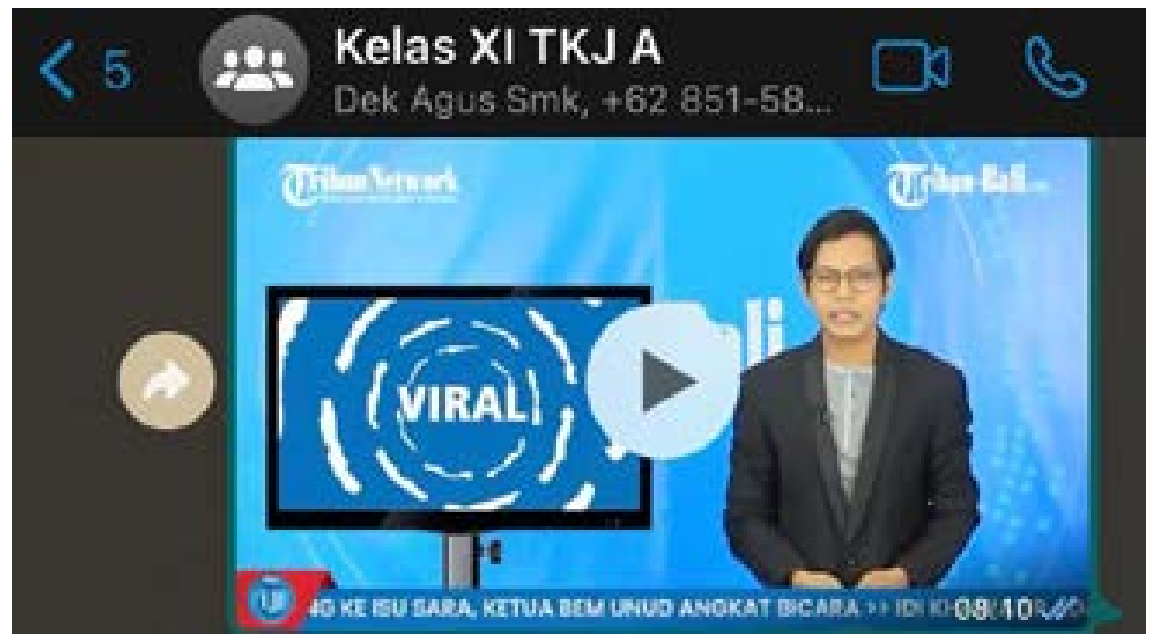

Gambar 1. Penggunaan media audio visual melalui whatsapp grup

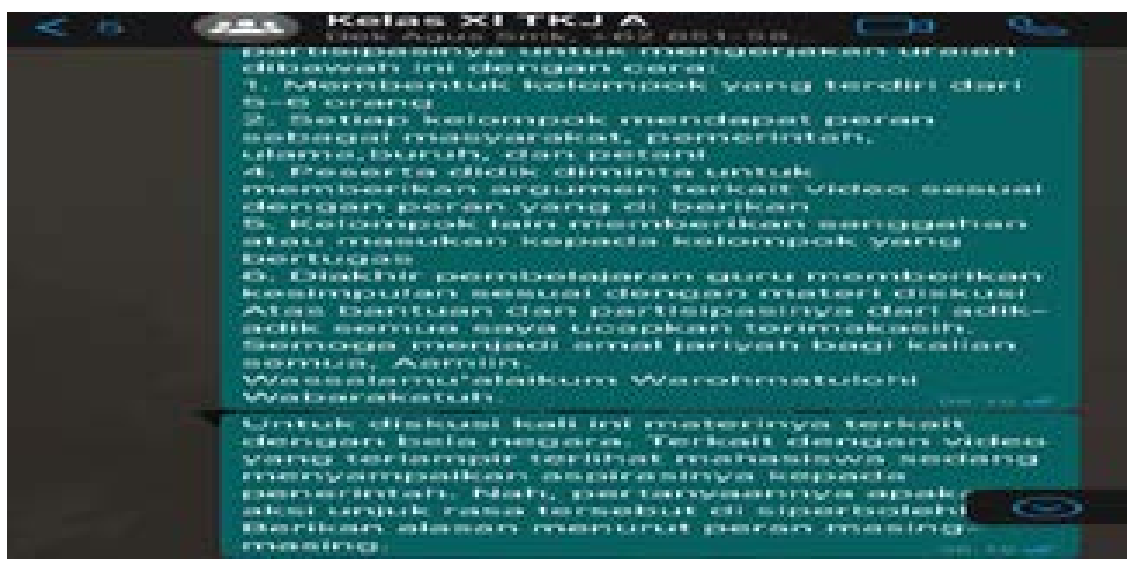

Gambar 2. Penggunaan strategi point counterpoint melalui whatsapp grup

\section{PENUTUP}

Implementasi media audio visual untuk meningkatkan critical thinking siswa menggunakan strategi point counterpoint memiliki beberapa tahap yaitu memberikan materi melalui grub WhatsApp berupa video, pembahasan materi dengan kelompok, dan simpulan dari guru agar siswa memahami materi 
yang telah disampaikan. Efektivitas implementasi media audio visual untuk meningkatkan critical thinking siswa menggunakan strategi point counterpoint terbukti efektif, hal ini dibuktikan dari hasil data yang diperoleh dari pretest 54,5 dan posttest 81,6 . Kendala yang dihadapi yaitu kendala waktu, kendala jaringan, dan persediaan kuota internet siswa yang terbatas. Solusi yang dapat dilakukan adalah dengan memanfaatkan waktu yang ada, proses pembelajaran dilakukan melalui WhatsApp Group, dan memberikan batas waktu pengerjaan. 


\section{DAFTAR PUSTAKA}

Arsyad, Azhar. Media Pembelajaran. Jakarta: Rajawali Press, 2011.

Djou, ridwan a. "PEMANFAATAN INTERNET DALAM PEMBELAJARAN PENDIDIKAN PANCASILA DAN KEWARGANEGARAAN UNTUK MEMBANGUN KARAKTER SISWA," 2016.

Faiz, F. Thinking Skill (Pengantar Menuju Berpikir). Yogyakarta: Suka Press, 2012.

Feni Nazela, Zulhaini, Helbi Akbar. "Penerapan Metode Pembelajaran Kooperatif Tipe Point Counter Point Dalam Meningkatkan Motivasi Belajar Siswa Kelas Viii a Pada Mata Pelajaran Sejarah Kebudayaan Islam Di Mts Negeri Sentajo Filial Singingi Kecamatan Singingi Kabupaten Kuantan Singingi,” 2019. http://ejournal.uniks.ac.id/Index.Php/Alhikmah/ Article/View/499.

FITRIANITA, YULIA. "Peningkatan Minat Belajar Siswa Pada Pembelajaran Ips Di Kelas Iva Dengan Strategi Point Counter Point Sd Negeri 28 Batang Anai Palapa Saiyo." Universitas Bung Hatta, 2014.

Hapsari, Laela Dwi. "PENGEMBANGAN MODEL PEMBELAJARAN ROLE PLAYING DENGAN STRATEGI POINT-COUNTER-POINT UNTUK MENINGKATKAN KEMAMPUAN BERPIKIR KRITIS SISWA (STUDI KASUS PADA KELAS X IIS 2 SMA NEGERI 1 UNGARAN MATA PELAJARAN SOSIOLOGI TAHUN 2015/2016)." Journal of Chemical Information and Modeling 53, no. 9 (2013): 1689-99.

Haryanti, Yuyun Dwi. "Model Problem Based Learning Membangun Kemampuan Berpikir Kritis Siswa Sekolah Dasar.” Jurnal Cakrawala Pendas, 2017. https://doi.org/10.31949/jcp.v3i2.596.

HASNUR, MUHAMMAD ARIF. "Penerapan Strategi Point Counter Point

Untuk Meningkatkan Kemampuan Berpikir Kritis Siswa Pada Tema Makanan Sehat Muatan Ips Kelas V Madrasah Ibtidaiyah Al-Ikhwan Pekanbaru," 2020.

Iranto, Dicky, and S Suparno. "The Effects of Pbl Method Using the Hypermedia To the Students' Critical Thinking Skill on the Social Studies Subject." 
Jurnal Pendidikan Ekonomi Dan Bisnis (JPEB) 2, no. 2 (2014): 40. https:// doi.org/10.21009/jpeb.002.2.3.

Kustandi, C., Sucipto, B., \& Sikumbang, R. Media Pembelajaran: Manual Dan Digital (2nd Ed.). Bogor: Ghalia Indonesia, 2013.

Lestari, Rahayu. "Bimbingan Kelompok Dengan Teknik Mind Mapping Untuk Meningkatkan Kemampuan Critical Thinking Dan Career Decision," 2019.

Lusyawati, Ennis dalam Lesy. "ANALISIS KEMAMPUAN BERPIKIR KRITIS SISWA SMA MATERI ALAT INDERA MELALUI MODEL PEMBELAJARAN INQUIRY PICTORIAL RIDDLE," 2017.

Menteri Pendidikan Nasional RI. Peraturan Menteri Pendidikan Nasional RI Nomor 24 Tahun 2006 tentang Sistem Pendidikan Nasional (2006).

Muhibbin, Achmad, Achmad Fathoni, Zainal Arifin, and Suliadi Firdaus Sufahani. "Data Analysis on Multiple-Intelligences as a Basis of Mapping and Increasing Independent Assignment Score in Civic Education Learning Based on Controversial Issues in Mass Media." International Journal of Scientific and Technology Research 8, no. 9 (2019): 621-26.

Mursini. Apresiasi Dan Pembelajaran Sastra Anak-Anak. Bandung: Cipta Pustaka Media Perintis, 2011.

Pendidikan, Departemen. Undang-Undang Nomor 20 Tahun 2003 Tentang Sistem Pendidikan Nasional, 33 Jakarta: Depdiknas $§(2003)$. https:// referensi.elsam.or.id/2014/11/uu-nomor-20-tahun-2003-tentang-sistempendidikan-nasional/.

Rachmantika, Arfika Riestyan, and Wardono. "Peran Kemampuan Berpikir Kritis Siswa Pada Pembelajaran Matematika Dengan Pemecahan Masalah.” In Prosiding Seminar Nasional Matematika, 2:441, 2019.

Redhana, I Wayan. "Model Pembelajaran Berbasis Masalah Dan Pertanyaan Socratik Untuk Meningkatkan Keterampilan Berpikir Kritis Siswa." Jurnal Cakrawala Pendidikan, no. 3 (2013). https://doi.org/10.21831/ cp.v0i3.1136.

Rohani, Ahmad. Media Instruksional Edukatif. Jakarta: Rineka Cipta, 1997.

Rosantiana NM. "Penerapan Media Audio Visual Untuk Meningkatkan Hasil Belajar Siswa Kelas VII Pada Pembelajaran PKn Di SMP Muhammadiyah 4 Semarang." Penerapan Media Audio Visual Untuk Meningkatkan Hasil 
252 Ahmad Muhibbin dkk, Implementasi Media Audio Visual

Belajar Siswa Kelas VII Pada Pembelajaran PKn Di SMP Muhammadiyah 4 Semarang. 1, no. 2 (2016): 1-58.

Silberman, Melvin L. Active Learning: 101 Cara Belajar Siswa Aktif Terjemahan Raisul Muttaqien. Bandung: Nuansa, 2014.

Sugiyono. Metode Penelitian Kuantitatif, Kualitatif Dan $R \& D$. Bandung: Alfabeta, 2018.

Suprianto, Edy. "Implementasi Media Audio Visual Untuk Meningkatkan Kemampuan Menulis Teks Eksplanasi." Trapsila: Jurnal Pendidikan Dasar 1, no. 02 (2020): 22. https://doi.org/10.30742/tpd.v1i02.810.

Susilowati, Rini. "Penerapan Model Problem Based Learning Berbantu Media Audio Visual Untuk Meningkatkan Berpikir Kritis Kelas 4 Sd.” Jurnal Imiah Pendidikan Dan Pembelajaran 2, no. 1 (2018). https://doi.org/10.23887/ jipp.v2i1.13870.

Suwadi, Suwadi. "Penerapan Strategi Pembelajaran Point-Counterpoint Bervariasi Untuk Meningkatkan Daya Kritis Dan Hasil Belajar Pada Mata Pelajaran PKn Topik Usaha Pembelaan Negara Bagi Siswa Kelas IX E SMP Negeri 1 Mojosongo.” Teknodika 14, no. 1 (2016): 69. https://doi. org/10.20961/teknodika.v14i1.34703.

Syaribuddin, S., I. Khaldun, and M. Musri. "Penerapan Model Pembelajaran Problem Based Learning (Pbl) Dengan Media Audio Visual Pada Materi Ikatan Kimia Terhadap Penguasaan Konsep Dan Berpikir Kritis Peserta Didik Sma Negeri 1 Panga." Jurnal Pendidikan Sains Indonesia (Indonesian Journal of Science Education) 4, no. 2 (2016): 96-105.

Widarto, Pardjono, and Noto Widodo. "Pengembangan Model Pembelajaran." Cakrawala Pendidikan XXXI, no. 3 (2012): 409-23. 